\title{
A DICOTOMIA EXISTENTE NA PRÁTICA DOS EDUCADORES SOCIAIS NO ÂMBITO DO ACOLHIMENTO INSTITUCIONAL: DIFERENÇAS ENTRE CUIDADOR SOCIAL E EDUCADOR SOCIAL NO SERVIÇO DE ACOLHIMENTO INSTITUCIONAL
}

\author{
THE DICHOTOMY THAT EXISTS IN THE PRACTICE OF SOCIAL EDUCATORS \\ WITHIN INSTITUTIONAL HOSTING: DIFFERENCES BETWEEN SOCIAL \\ CAREGIVER AND SOCIAL EDUCATOR IN THE INSTITUTIONAL HOSTING SERVICE
}

\section{LA DICOTOMÍA EXISTENTE EN LA PRÁCTICA DE LOS EDUCADORES SOCIALES EN EL ÁMBITO DEL ACOGIMIENTO INSTITUCIONAL: DIFERENCIAS ENTRE CUIDADOR SOCIAL Y EDUCADOR SOCIAL EN EL SERVICIO DE ACOGIMIENTO INSTITUCIONAL}

Tiago Marques do Carmo*

\begin{abstract}
Resumo: O presente trabalho tem por objetivo discorrer sobre a prática interdisciplinar do Cuidador Social e do Educador Social que, apesar de possuírem nomes muito similares, não desempenham o mesmo papel no âmbito do acolhimento institucional. A pesquisa é parte do Trabalho de Conclusão de Curso de Bacharelado em Serviço Social, da Universidade Estadual de Ponta Grossa, que expressa a prática no campo da Política de Assistência Social. Devido à natureza do objeto de estudo qualitativo, foi empregado o uso de questionário semi-estruturado, referente ao levantamento de informações sobre o universo do acolhimento institucional. Apesar da similaridade das atividades dos trabalhadores sociais, o avanço das políticas públicas tem ampliado o diálogo com diversas camadas da sociedade civil e do poder governamental, concebendo o Educador Social como forte representante da Educação Social-Pedagogia Social.
\end{abstract}

Palavras-chave: Educador Social. Cuidador Social. Assistência Social.

Abstract: This paper aims to discuss the interdisciplinary practice of the Social Caregiver and the Social Educator who, despite having very similar names, do not play the same role in the institutional hosting. The research is part of the Conclusion Work of a Bachelor's Degree course in Social Work, from the State University of Ponta Grossa, which expresses the practice in the field of Social Assistance Policy. Due to the nature of the object of qualitative study, the use of a semi-structured questionnaire was used, referring to the collection of information about the institutional host universe. Despite the similarity of the activities of social workers, the advancement of public policies has broadened the dialogue with several layers of civil society and governmental power, conceiving the Social Educator as a strong representative of Social Education-Social Pedagogy.

Keywords: Social Educator. Social Caregiver. Social Assistance.

Resumen: El presente trabajo tiene por objetivo disertar sobre la práctica interdisciplinar del Cuidador Social y del Educador Social que, a pesar de poseyeren nombres muy similares, no desempeñan el mismo papel en el ámbito del acogimiento institucional. La pesquisa forma parte del Trabajo de

\footnotetext{
* Assistente Social formado pela UEPG. Educador Social na Prefeitura Municipal de Ponta Grossa. E-mail: tiagomarquesdocarmo@gmail.com
} 
Conclusión de Curso de Bachillerato Superior en Servicio Social, de la Universidade Estadual de Ponta Grossa, que expresa la práctica en el campo de la Política de Asistencia Social. Debido a la naturaleza del objeto de estudio cualitativo, fue empleado el uso de cuestionario semi-estructurado, referente al levantamiento de informaciones sobre el universo del acogimiento institucional. A pesar de la similitud de las actividades de los trabajadores sociales, el avance de las políticas públicas ha ampliado el diálogo con diversas capas de la sociedad civil y del poder gubernamental, concibiendo el Educador Social como fuerte representante de la Educación Social-Pedagogía Social.

Palabras claves: Educador Social. Cuidador Social. Asistencia Social.

\section{O Serviço de Acolhimento Institucional na perspectiva do Sistema Único de Assistência Social no contexto brasileiro}

Depois da aprovação da Constituição Federal de 1988, a Assistência Social inserida no campo das políticas públicas, sendo um dos pilares do modelo de Seguridade Social, compreendidos como "conjunto integrado de ações de iniciativa dos Poderes Públicos e da sociedade, destinadas a assegurar os direitos relativos à saúde, à previdência e à assistência social”. (BRASIL, 1988).

De acordo com Fleury (2005, p. 453), essa nova lógica de garantia de direitos demonstra que, com a presença das políticas públicas não-contributivas, no caso da Assistência Social e Saúde, todos os indivíduos tem acesso igualitário, não sendo uma questão relacionada à contribuição, como anteriormente era previsto apenas aos beneficiários da Previdência Social.

Na década de 1990 surgiu a necessidade da Assistência Social ser reconhecida como política pública de garantia de direitos, ocorrendo a aprovação da Lei $n^{0}$ 8.742, de 07 de Dezembro de 1993, a Lei Orgânica de Assistência Social (LOAS). Segundo Sposati (2007, p. 69), a LOAS concebe ao Estado a responsabilidade da gestão da referida política social, garantindo a condição de cidadania à todos os sujeitos que dela necessitarem, entretanto, demorou algum tempo para ser implementada integralmente.

O processo de estruturação teve contribuições significativas a partir das deliberações realizadas durante a IV Conferência Nacional de Assistência Social, apresentando as principais conquistas para a cidadania durante a primeira década de existência da LOAS, a partir da mobilização de vários movimentos sociais, compondo uma nova agenda social, fortalecendo e ampliando o diálogo entre o governo e movimentos sociais. (BRASIL, 2003, p. 7).

Sequencialmente, com a Resolução $n^{\circ}$ 145, de 15 de outubro de 2004, fica instituída a Política Nacional de Assistência Social (PNAS) em todo o território brasileiro, configurada como política pública, objetivando o atendimento às necessidades dos cidadãos que dela necessitarem, sem nenhuma forma de contribuição prévia. (BRASIL, 2009, p. 15).

De acordo com Silveira (2007, p. 66) a funcionalidade da Política Pública de Assistência Social está dividida em Proteção Social Básica (PSB) e Proteção Social Especial (PSE), considerando o nível de complexidade existente entre os modelos de proteção e reordenação dos serviços socioassistenciais.

A regulamentação do Sistema Único de Assistência Social (SUAS) somente ocorreu com a aprovação da Resolução $n^{0} 130$, de 15 de Julho de 2005, a Norma Operacional Básica do SUAS (NOB SUAS). 
Segundo Silveira (2007, p. 61), a operacionalização do SUAS permitiu que o formato de atendimento dos equipamentos socioassistenciais aos sujeitos de direitos sejam articulados, descentralizadamente, conforme seu território de abrangência, estruturando o atendimento por "níveis de complexidade e porte de município, com repactuação de responsabilidade entre os entes federados”.

Nesse novo modelo da Assistência Social foram elaboradas normativas que complementam o acesso aos direitos sociais e a gestão do trabalho nos equipamentos do SUAS que, dentre elas, podemos destacar a Tipificação Nacional de Serviços Socioassistenciais, aprovada pela Resolução $n^{0} 109$, de 11 de Novembro de 2009, objetivando a padronização dos serviços ofertados nos equipamentos do SUAS, de acordo com o modelo de proteção social. (BRASIL, 2014, p. 5).

No que se refere ao modelo de Proteção Social Especial, o atendimento direciona sua prática aos indivíduos e/ou famílias que estejam em situação de vulnerabilidade social e/ ou risco pessoal e social, decorrente da fragilização dos vínculos familiares e comunitários. (BRASIL, 2014, p. 44). Delimitaremos a discussão dos espaços socioassistenciais apenas às instituições de acolhimento para crianças e adolescentes, sendo este o universo de estudo em questão.

$\mathrm{O}$ acolhimento institucional tem trajetória impactante no cenário brasileiro, principalmente nos períodos posteriores à promulgação do Código de Menores de 1927, que separava os abrigados, conforme o gênero e sua condição peculiar, em situação de abandono ou delinquência. A referida lei destaca que os menores eram encaminhados à espaço especifico, passando pelos procedimentos institucionais e, mesmo que após examinado por equipe médica, seriam observados pelo período que fosse preciso. (BRASIL, 1927, n.p.).
Com o avanço das políticas de atendimento à Criança e ao Adolescente, considerando a promulgação da Constituição Federal de 1988 e, em seguida, da Lei n ${ }^{0}$ 8.069, de 13 de Julho de 1990, o Estatuto da Criança e do Adolescente, reordenando o modelo de intervenção a tais sujeitos no contexto brasileiro, contribuindo para a extinção do termo menor, anteriormente colocado como tutelado pelo Estado, mas assegura a figura de sujeitos de direitos. (FERREIRA et al., 2007, p. 219).

De acordo com Silva (2010, p. 43), a partir da promulgação do Estatuto da Criança e do Adolescente, a cultura do abrigamento, por parte de entidades com perfil assistencialista é deixado de lado, passando a ser visto pela ótica da proteção integral e promoção dos direitos sociais. Um resultado disso está associado na alteração da referida legislação que, com a Lei $n^{\circ} 12.010$, de 03 de Agosto de 2009, vigorando o modelo de Acolhimento Institucional, objetivando que a permanência institucional seja o mínimo tempo possível e adotando estratégias para o retorno ao convívio familiar. (BRASIL, 2009, n.p.).

Devido às questões que envolvem o acolhimento institucional estarem voltadas a situações que apresentam alguma forma de violações de direitos, nesta pesquisa direcionaremos o olhar à Proteção Social Especial que, na divisão de Alta Complexidade, atendem indivíduos que apresentem o rompimento de vínculos familiares e/ou comunitários, necessitando o acolhimento institucional para o provimento de suas necessidades básicas. (PEREIRA, 2007, p. 76).

Destacamos que a composição das equipes dos serviços de acolhimento institucional está prevista na Resolução $n^{\circ} 269$, de 13 de Dezembro de 2006, a NOB-RH/ SUAS, dada da seguinte maneira: 01 coordenador, com formação em nível superior ou médio, atendendo o limite de 20 acolhidos; 01 
cuidador de nível médio e 01 auxiliar cuidador para cada grupo de 10 acolhidos, devendo possuir nível fundamental. (BRASIL, 2011, p. 33-34).

A dicotomia entre as funções de Educador Social e Cuidador Social está expressa através da NOB-RH/SUAS, direcionando o olhar apenas na perspectiva dos Cuidadores Sociais, contudo, devido aos ocorridos a partir das deliberações da VIII Conferência Nacional de Assistência Social, em 2011, culminaram na aprovação da Resolução no 9, de 15 de Abril de 2014, do Conselho Nacional de Assistência Social, ampliando esse debate. (BRASIL, 2014, p. 3).

Quadro 1: Principais atribuições dos Cuidadores Sociais e Educadores Sociais, a partir das deliberações da VIII Conferência Nacional De Assistência Social (2011)

\begin{tabular}{|c|c|}
\hline CUIDADORES SOCIAIS & EDUCADORES SOCIAIS \\
\hline $\begin{array}{l}\text { Desenvolvimento de atividades de cuidados } \\
\text { básicos essenciais para a vida diária e } \\
\text { instrumentais de autonomia e participação } \\
\text { social dos usuários, a partir de diferentes } \\
\text { formas e metodologias, contemplando as } \\
\text { dimensões individuais e coletivas. }\end{array}$ & $\begin{array}{l}\text { Desenvolvimento de atividades socioeducativas } \\
\text { e de fortalecimento das relações sociais visando } \\
\text { a garantia e proteção dos direitos referentes } \\
\text { aos indivíduos e famílias em situações de } \\
\text { vulnerabilidade e/ou risco social e pessoal, } \\
\text { contribuindo para o fortalecimento da função } \\
\text { protetiva da família. }\end{array}$ \\
\hline $\begin{array}{l}\text { Desenvolvimento de atividades referentes ao } \\
\text { acolhimento, proteção integral e promoção da } \\
\text { autonomia e autoestima dos usuários. Atuação } \\
\text { na recepção dos usuários possibilitando uma } \\
\text { ambiência acolhedora. }\end{array}$ & $\begin{array}{l}\text { Desenvolvimento de atividades instrumentais e } \\
\text { registro para assegurar direitos, fortalecimento da } \\
\text { autonomia, autoestima, convívio e participação } \\
\text { social dos usuários, a partir de diferentes formas } \\
\text { e metodologias, contemplando as dimensões } \\
\text { individuais e coletivas. }\end{array}$ \\
\hline $\begin{array}{l}\text { Apoio e monitoramento dos cuidados } \\
\text { referentes à moradia, como organização } \\
\text { e limpeza do ambiente e preparação dos } \\
\text { alimentos, bem como as atividades diárias } \\
\text { dos usuários como higiene, organização, } \\
\text { cuidado alimentação e lazer, assim como } \\
\text { acompanhamento dos usuários em atividades } \\
\text { externas. }\end{array}$ & $\begin{array}{l}\text { Apoio e participação no planejamento das ações, } \\
\text { além de organização e desenvolvimento de oficinas. } \\
\text { Atividades individuais e coletivas de vivência } \\
\text { nas unidades e/ou nas comunidades, além do } \\
\text { acompanhamento, orientação e monitoramento dos } \\
\text { usuários na execução das atividades. }\end{array}$ \\
\hline $\begin{array}{l}\text { Identificação das necessidades e demandas } \\
\text { dos usuários, apoiando o planejamento } \\
\text { e organização de sua rotina diária nas } \\
\text { instituições. }\end{array}$ & $\begin{array}{l}\text { Auxílio na organização de eventos artísticos, } \\
\text { lúdicos e culturais nos espaços socioassistenciais ou } \\
\text { comunitários. }\end{array}$ \\
\hline $\begin{array}{l}\text { Auxílio nas orientações, informações, } \\
\text { encaminhamentos e acesso a serviços, } \\
\text { programas, projetos, benefícios, transferência } \\
\text { de renda, ao mundo do trabalho por meio de } \\
\text { articulação com políticas afetas ao trabalho e } \\
\text { ao emprego, dentre outras políticas públicas, } \\
\text { contribuindo para o usufruto de direitos } \\
\text { sociais. }\end{array}$ & $\begin{array}{l}\text { Atuação na orientação, informação, } \\
\text { encaminhamentos e acesso a serviços, programas, } \\
\text { projetos, benefícios, transferência de renda, ao } \\
\text { mundo do trabalho por meio de articulação com } \\
\text { políticas afetas ao trabalho e ao emprego, dentre } \\
\text { outras políticas públicas, contribuindo para o } \\
\text { usufruto de direitos sociais. }\end{array}$ \\
\hline
\end{tabular}


Conclusão

\begin{tabular}{l|l}
\hline CUIDADORES SOCIAIS & EDUCADORES SOCIAIS \\
\hline $\begin{array}{l}\text { Apoio no fortalecimento e potencialização } \\
\text { da convivência familiar e comunitária, } \\
\text { estabelecendo e/ou potencializando vínculos } \\
\text { entre os usuários, profissionais e familiares, } \\
\begin{array}{l}\text { possibilitando reconhecimento dos direitos } \\
\text { inerentes à pessoa humana }\end{array}\end{array}$ & $\begin{array}{l}\text { Apoio na elaboração de registros das atividades } \\
\text { desenvolvidas, subsidiando a equipe no } \\
\text { relacionamento com os órgãos de defesa de direitos e } \\
\text { para o preenchimento do Plano de Acompanhamento } \\
\text { Individual e/ou familiar. }\end{array}$ \\
\hline
\end{tabular}

Fonte: BRASIL. Conselho Nacional de Assistência Social. Resolução nº 9, de 15 de Abril de 2011. Ratifica e reconhece as ocupações e as áreas de ocupações profissionais de ensino médio e fundamental do Sistema Único de Assistência Social - SUAS, em consonância com a Norma Operacional Básica de Recursos Humanos do SUAS - NOB-RH/SUAS. Disponível em:< http://www.mds.gov.br/cnas/legislacao/ resolucoes/arquivos-2014/cnas-2014-009-15-04-2014.pdf/download>. Acesso em: 07 Dez. 2017. Org.: Pelo autor.

As particularidades referentes à atuação dos trabalhadores nos espaços socioassistenciais do SUAS consistem em atividades que visem o suprimento de necessidades cotidianas e na potencialização das relações pessoais e familiares dos usuários atendidos, no caso do Cuidador Social, enquanto o Educador Social tem direcionamento às demandas de usuários em situação de vulnerabilidade e/ ou risco social/pessoal, além de auxiliar na elaboração de atividades de empoderamento dos sujeitos. (BRASIL, 2014, p. 3-5).

Com o objetivo do aprimoramento constante das equipes de trabalho na gestão de trabalho do SUAS, é constituída a Política Nacional de Educação Permanente do SUAS (PNEP/SUAS), que apresentava como temática principal: "Avançando na consolidação do Sistema Único de Assistência Social - SUAS com a valorização dos trabalhadores e a qualificação da gestão, dos serviços, programas, projetos e benefícios”. (BRASIL, 2013, p. 25).

Albuquerque e Silva (2014, p. 95) discorrem sobre a importância da capacitação permanente dos profissionais de nível médio, neste caso o Educador Social, que nem sempre apresentam formação específica para o campo de atuação, porém apresenta um resgate histórico de comprometimento e responsabilidades em conjunto aos demais trabalhadores do Sistema Único de Assistência Social.

De acordo com Couto et al. (2012, p. 258) a NOB-RH/SUAS, enquanto normativa integrante da "política de Recursos Humanos na Assistência”, não deve apresentar preocupação apenas nas atuações intersetoriais e interdisciplinares das equipes de trabalho, mas também nos investimentos de valorização profissional e no enfrentamento às precariedades presentes no mundo do trabalho.

\section{A realidade institucional da Central de Acolhimento Provisória para adolescentes do Município de Ponta Grossa/PR.}

O universo institucional da Central de Acolhimento Provisório é composto pelo encaminhamento realizado pelos Conselhos Tutelares, em razão do rompimento dos vínculos familiares, entretanto, muitas vezes os trabalhadores não apresentam amplo conhecimento sobre as diversas situações referentes à sua atuação.

A trajetória histórica institucional do universo de pesquisa teve início em setembro de 1998, na Central de Atendimento à Criança e por finalidade o atendimento 
às crianças e adolescentes encaminhados pela Vara da Infância e Juventude, além do Conselho Tutelar. A referida instituição é caracterizada como uma entidade pública, sem fins lucrativos, conveniada com a Secretaria Municipal de Assistência Social Departamento da Criança e do Adolescente, Associação de Meninos e Meninas de Ponta Grossa (ASSOMA) e Fundação PROAMOR de Assistência ao Menor.

Com a intenção do atendimento direcionado à questão do acolhimento institucional, houve a separação do atendimento público em dois espaços: a Casa de Abrigo Feminino Irmã Mari Leticia Schamne, destinada ao sexo feminino, e a Central de Atendimento à Criança e ao Adolescente, destinada ao sexo masculino.

Ambas as entidades iniciaram suas atividades com crianças e adolescentes, com idade entre 07 anos completos e 18 anos incompletos, conforme previsto no Estatuto da Criança e do Adolescente.

Com a Resolução $\mathrm{n}^{\circ}$ 07, de 10 de Março de 2016, do Conselho Municipal de Assistência Social (CMAS), ocorre o repasse do Serviço de Acolhimento Institucional Provisório para Crianças e Adolescentes Governamental à Organização NãoGovernamental Jovens com uma Missão (JOCUM), reconfigurando o atendimento no município, iniciando suas atividades em 01 de Fevereiro de 2016.

Contudo, no mesmo ano houve o cancelamento do convênio, por parte da Organização Não-Governamental JOCUM, retornando em 20 de Junho de 2016 a execução do Serviço de Acolhimento Institucional à gestão governamental municipal, conforme disposto na Resolução no 12, de 19 de Maio de 2016, do Conselho Municipal de Assistência Social.
Com o retorno das atividades à gestão governamental, a entidade se unificou e passou a ser denominada Central de Acolhimento Provisório, atendendo adolescentes, de ambos os sexos, com idade entre 12 anos completos e 18 anos incompletos, atualmente situados na estrutura física que a unidade masculina estava instalada.

\section{Metodologia}

Referente ao processo investigativo, Minayo (1999, p. 17) destaca o exercício basilar científico "na sua indagação e construção da realidade. É a pesquisa que alimenta a atividade de ensino e a atualiza frente à realidade do mundo. Portanto, embora seja uma prática teórica, a pesquisa vincula pensamento e ação", sendo que muitos questionamentos presentes nesse campo de estudos são considerados pragmáticos, tendo sua representatividade através dos discursos dos sujeitos envolvidos, nesse caso os próprios trabalhadores sociais.

Devido à natureza dos fatos pesquisados, foi utilizada uma pesquisa qualitativa, justificada, sobretudo, por ser uma forma adequada para o entendimento da essência do fenômeno social. Tanto assim é que existem problemas que podem ser investigados por meio de metodologia quantitativa, e há outros que exigem diferentes enfoques e, consequentemente, uma metodologia de conotação qualitativa. (RICHARDSON et al., 2008, p. 90-91).

Durante o processo investigativo, foram utilizadas os procedimentos metodológicos de levantamento bibliográfico e revisão de literatura que, conforme menciona Lakatos e Marconi (2003, p. 225), nenhum estudo cientifico é iniciado do nada, existindo elementos presentes em alguns modelos de pesquisa que contenham dados similares e/ou 
suplementares, envolvendo características do assunto pretendido, sendo necessário a listagem de documentos e demais obras temáticas, objetivando o aprimoramento da pesquisa.

O universo de pesquisa, foi a Central de Acolhimento Provisório, que presta atendimento à crianças e adolescentes com idade entre 07 anos completos e 18 anos incompletos. Na coleta de dados foram utilizados questionários semiestruturados, fornecendo informações sobre as particularidades existentes da categoria elencada, composta por questões abertas e fechadas, permitindo dar voz aos sujeitos do estudo, direcionando tanto aos aspectos objetivos como subjetivos do estudo realizado. (RICHARDSON et al., 2008, p. 193).

Os sujeitos de pesquisa foram selecionados a partir dos critérios de maior tempo de atuação na função e, em seguida, maior tempo de permanência na entidade, objetivando uma abordagem sustentada pelo histórico de convivência com adolescentes, compreendendo seu vínculo institucional. Dentro dessa perspectiva, foram selecionados 03 (três) homens e 03 (três) mulheres que desempenham a função de Educadores Sociais.

Sequencialmente à descrição do método de pesquisa empregado, será discorrido sobre as diferenças existentes entre as funções de Cuidador Social e Educador Social, na perspectiva das normativas vigentes do SUAS, para que, finalmente, seja exposto os relatos dos Educadores Sociais acerca do seu cotidiano institucional.

\section{Resultados}

Na questão referente à descrição das principais atribuições referentes ao vinculo institucional, expomos o elucidado pela Educadora 2, colocando a realização do acolhimento dos adolescentes que, além do fornecimento de roupas e materiais de higiene durante a permanência na entidade, consistem em dar aos acolhidos todas as informações sobre o funcionamento da casa, bem como seus direitos e deveres. Vigiar constantemente todas as ações dos acolhidos. Medicar, quando necessário e mediante prescrição médica. Acompanhá-los quando solicitado às dependências da SMAS.

Nesse sentido, expressamos o contido no Regimento Interno da Central de Atendimento à Criança e ao Adolescente, referente aos atendimentos realizados na entidade, elaborado em 2013, porém, utilizado até os dias atuais, sendo pautado pelo Estatuto da Criança e do Adolescente que, em seu Art. $6^{\circ}$, define que a compreensão da legislação vigente, deverá sempre integrar os elementos componentes da garantia de direitos dos adolescentes, em face de sua peculiaridade e seu processo de desenvolvimento. (BRASIL, 1990, n.p.).

O Educador 1 também apresenta semelhança quanto à exposição dada pela trabalhadora acima, mencionando que, dentre suas principais atribuições está o acolhimento institucional de crianças e adolescentes em abrigo provisório. Em casos onde os infantes geralmente são encaminhados pelo Conselho Tutelar em situação de vulnerabilidade, bem como o Educador 3 destaca o papel de cuidar e zelar pelas crianças e adolescentes que são acolhidos.

Observando atentamente às falas destes trabalhadores, constatamos que, apesar de convivermos numa época de garantia de direitos, ainda persistem o uso de terminologias que remetem à época do Código de Menores, consistido por seu caráter punitivo e excludente.

No relato da Educadora 3 é expressado a orientação sobre os cuidados com os acolhidos por parte dos Educadores Sociais, que podem 
ser observadas no momento do acolhimento, além da realização da revista e observação quanto a existência de feridas, hematomas e/ ou porte de substâncias psicoativas, deverão ser feitas todas as anotações necessárias, orientar na higiene pessoal, regras da instituição, direitos e deveres e manter vigilância constante no turno de trabalho. Fazer relatórios diários de todos os acontecimentos, também correspondendo à colocação dada pelo Educador 2, mencionando sua experiência em realizar abrigamentos/desabrigamentos; monitorar a rotina dos acolhidos; acompanhar os acolhidos nas saídas externas.

A presença das particularidades mencionadas pelos sujeitos acima poderão ser observadas nos editais de Concurso Público $\mathrm{n}^{\circ}$ 004/2009 e 004/2010, considerando que desenvolvem atividades de cuidado e vigilância constante no seu turno de trabalho, assegurando o bem-estar dos próprios adolescentes. Em caso de adolescentes que sejam usuários de substâncias psicoativas, os Educadores Sociais deverão comunicar à equipe técnica, intermediando o encaminhamento para atendimento aos equipamentos da Política Pública Intersetorial de Saúde Mental, no caso a unidade do Centro de Atenção Psicossocial Infanto-juvenil (CAPSi).

A Educadora 1 concebe uma abordagem voltada à manutenção dos direitos sociais básicos, tais como a higiene pessoal $e$ materiais, uma boa alimentação etc, e acompanhamento quando necessário a hospitais, internações e lazer, cuidados com os acolhidos, procurando atender suas necessidades necessárias para o ambiente aonde estão vivendo no momento (abrigos). Os Educadores Sociais integram importante papel na manutenção dos direitos fundamentais de tais sujeitos, em razão da condição de vulnerabilidade e/ou risco social estão inseridos, cabendo a tais trabalhadores sociais o desempenho de ações que garantam sua emancipação social.
Através da exploração dos desafios encontrados diariamente no seu trabalho, evidenciamos na resposta da Educadora 2 alguns impasses presentes quanto ao desenvolvimento de sua atuação, tais como a ausência de equipe de trabalho no quadro funcional, proporcionando uma sobrecarga aos trabalhadores e trabalhadoras, pouca valorização dos educadores por parte do empregador, o que acaba resultando num desestímulo ao desempenhar a função; estrutura física não adequada para a permanência de acolhidos. Como permanecem o tempo todo fechados dentro da casa, acabam ficando estressados, o que causa certos transtornos.

Explicitamos, ainda, a complexidade do trabalho desenvolvido pelos Educadores Sociais, decorrente das peculiaridades dos encaminhamentos realizados à entidade, destacando que, segundo Caliman (2008, p. 19), tem origem de "uma necessidade da sociedade industrializada, enquanto nela se desenvolvem situações de risco e mal-estar social que se manifestam nas formas da pobreza, da marginalidade, do consumo de drogas, do abandono e da indiferença social”.

Na concepção do Educador 1, entre os desafios encontrados na sua prática, estão a instituição precária, com móveis antigos, estragados, poucos recursos, pouco material para desenvolver atividades, complementado pelo Educador 3, mencionando a falta de estrutura e lentidão para solução de determinados casos, implicando em obstáculos quanto ao processo emancipatório, não demonstrando por parte dos gestores públicos quanto ao fortalecimento das ações voltadas à área da criança e ao adolescente, conforme citado anteriormente.

Já a Educadora 3 declara a existência do despreparo dos trabalhadores para atuar na instituição, sensação de prisão dos acolhidos no abrigo, desejo de fuga por parte dos 
adolescentes e a ausência de acompanhamento as famílias após o retorno familiar, também justificando a resposta dada pelo Educador 2, consistida na conservação do equilíbrio psíquico/emocional; motivação; preservar e prestar um atendimento humanizado, sendo elementos que estão muito presentes, tanto na realidade dos adolescentes como dos próprios Educadores Sociais, que mantém uma relação direta, cotidiamente, devido ao tempo de convivência entre ambos.

Em relação à questão motivacional existente no referido espaço de trabalho, Miranda (2011, p. 33) descreve a necessidade do emprego de estratégias que visem a potencialização das práticas dos Educadores Sociais que, como qualquer outro funcionário, sentem necessidade de reconhecimento e incentivo, especialmente pelo fato de que a realidade pesquisada apresenta uma perspectiva dinâmica, caracterizada pela constante rotatividade dos adolescentes acolhidos. Destacamos, ainda que, não foram realizadas nomeações, referentes aos últimos editais para contratação de novos servidores municipais, devido ao termino do período, ocorrendo a última contratação em Março/2015. (PONTA GROSSA, 2015, n.p.).

A Educadora 1 complementa o pensamento destacado anteriormente pela Educadora 3 e pelo Educador 2, no sentido que tais trabalhadores devem ter boa saúde mental para atender as diferentes situações, como desavença familiar, como um caso muito mais sério como usuários dependentes químicos (droga, bebida) crianças que sofrem violência física e emocional, criança com transtornos psicológicos, usuários de medicamentos neurológicos.

De acordo com o documento de Orientações Técnicas para os Serviços de Acolhimento para Crianças e Adolescentes, é essencial que haja investimentos quanto à "capacitação e acompanhamento dos educadores/cuidadores", bem como de todos os profissionais atuantes no ambiente de trabalho, sendo "importante que seja oferecida capacitação inicial de qualidade, e formação continuada a tais profissionais, especialmente aqueles que têm contato direto com as crianças e adolescentes e suas famílias”. (BRASIL, 2009, p. 57).

Nessa perspectiva da preparação física e psicológica dos Educadores Sociais, conforme mencionado pela trabalhadora acima, associamos ao viés da capacitação permanente, seja na área da infância e juventude como na utilização dos diversos instrumentais de trabalho que, por terem um contato por um maior tempo com os acolhidos, cerca de 08 horas diárias, precisam ser qualificados constantemente sobre sua atuação.

\section{Conclusão}

Evidenciamos, ao decorrer do processo investigativo, a relação entre o exercício prática profissional do Educador Social e do Cuidador Social, ambos atuantes nos diversos equipamentos da Política Pública de Assistência Social, entretanto, desempenham práticas distintas, apesar de serem, culturalmente, associados. Pode ser observado a constante evolução da política pública, tanto no que se refere ao atendimento ao público alvo, tanto como na profissionalização dos trabalhadores e trabalhadoras no âmbito do SUAS, representando a importância do cuidado com aqueles que desempenham essa importante atribuição.

As indagações dos Educadores e Educadoras Sociais remetem à necessidade de uma atenção, por parte do poder público, no cumprimento das normas e diretrizes que compõe as garantias referentes aos sujeitos de direitos, além de proporcionar aos 
trabalhadores em tela, condições para que desempenhem esse importante papel que representam como integrantes do Sema de Garantia de Direitos da Criança e do Adolescente.

Destacamos, ainda, que a falta de trabalhadores no âmbito do acolhimento institucional, espaço marcado por várias questões peculiares, tanto pela trajetória de vida dos adolescentes encaminhados, que apresentam situações frágeis, como pela própria questão psicossocial dos próprios educadores sociais, possibilitam implicações no desempenho da função, devido à extrema carga de trabalho à que estão sujeitos.

\section{Referências}

ALBUQUERQUE, S. A.; SILVA, M. A. A educação permanente no SUAS: perspectivas e desafios. In: CRUS, J. F.; ALBUQUERQUE, S. A. Gestão do trabalho e educação permanente do SUAS em pauta. Brasília: MDS, 2014. p. 90-100.

BRASIL. Constituição (1988). Constituição da República Federativa do Brasil: promulgada em 5 de outubro de 1988. Disponível em: <http://www. planalto.gov.br/ccivil_03/constituicao/ constituicaocompilado.htm>. Acesso em: 07 dez. 2017.

Decreto $\mathrm{n}^{0}$ 17.943-A de 12 de Outubro de 1927. Consolida as leis de assistência e protecção a menores. Disponível em: < http://www.planalto.gov.br/ccivil_03/ decreto/1910-1929/d17943a.htm>. Acesso em: 07 dez. 2017.

. Lei $\mathbf{n}^{0}$ 12.010, de 03 de Agosto de 2009. Dispõe sobre adoção; altera as Leis $\mathrm{n}^{\text {os }}$ 8.069, de 13 de julho de 1990 - Estatuto da Criança e do Adolescente, 8.560, de 29 de dezembro de 1992; revoga dispositivos da Lei $\mathrm{n}^{\circ}$ 10.406, de 10 de janeiro de 2002
- Código Civil, e da Consolidação das Leis do Trabalho - CLT, aprovada pelo DecretoLei $\mathrm{n}^{0} 5.452$, de $1^{\circ}$ de maio de 1943 ; e dá outras providências. Disponível em: < http:// www.planalto.gov.br/ccivil_03/_ato20072010/2009/lei/112010.htm>. Acesso em: 07 dez. 2017.

\section{Lei $\mathrm{n}^{0}$ 8.742, de 07 de Dezembro}

de 1993. Dispõe sobre a organização da Assistência Social e dá outras providências. Disponível em: < http://www.planalto.gov. br/ccivil_03/leis/L8742.htm>. Acesso em: 07 dez. 2017.

. Lei $\mathbf{n}^{\circ}$ 8.069, de 13 de Julho de 1990. Dispõe sobre o Estatuto da Criança e do Adolescente e dá outras providências. Disponível em: <http://www.planalto.gov. br/ccivil_03/leis/L8069.htm>. Acesso em: 07 dez. 2017.

Ministério da Assistência Social. Conselho Nacional de Assistência Social. Relatório da IV Conferência Nacional de Assistência Social. Disponível em: < http://www.mds.gov.br/cnas/conferenciasnacionais/iv-conferencia-nacional/ conferencias-nacionais/iv-conferencianacional/relatorio-final-iv-conferencianacional.pdf $>$. Acesso em: 07 dez. 2017.

Ministério do Desenvolvimento Social e Combate a Fome. Secretaria Nacional de Assistência Social. Política Nacional de Assistência Social-PNAS/2004 e Norma Operacional Básica- NOB/SUAS. Disponível em: < http://www.mds.gov.br/ webarquivos/publicacao/assistencia_social/ Normativas/PNAS2004.pdf>. Acesso em: 07 dez. 2017.

Ministério do Desenvolvimento Social e Combate A Fome. Secretaria Nacional de Assistência Social. Tipificação Nacional de Serviços Socioassistenciais. Disponível em: <http://www.mds.gov.br/ 
webarquivos/publicacao/assistencia_social/ Normativas/tipificacao.pdf $>$. Acesso em: 07 dez. 2017.

- Ministério do Desenvolvimento Social e Combate A Fome. Secretaria Nacional de Assistência Social. NOB-RH/ SUAS: anotada e comentada. Disponível em: < http://www.mds.gov.br/webarquivos/ publicacao/assistencia_social/Normativas/ NOB-RH_SUAS_Anotada_Comentada.pdf >. Acesso em: 07 dez. 2017.

Ministério Do Desenvolvimento Social E Combate A Fome. Secretaria Nacional de Assistência Social. Política Nacional de Educação Permanente do SUAS. Disponível em: < http://www.mds. gov.br/webarquivos/publicacao/assistencia_ social/Normativas/Politica-nacional-deEducacao-permanente.pdf $>$. Acesso em: 07 dez. 2017.

Resolução $n^{0}$ 9, de 15 de Abril de 2014. Ratifica e reconhece as ocupações e as áreas de ocupações profissionais de ensino médio e fundamental do Sistema Único de Assistência Social - SUAS, em consonância com a Norma Operacional Básica de Recursos Humanos do SUAS - NOB-RH/ SUAS. Diário Oficial da União, Brasília, 16 abr. 2014. Disponível em: < http://www. mds.gov.br/cnas/legislacao/resolucoes/ arquivos-2014/cnas-2014-009-15-04-2014. pdf/download>. Acesso em: 07 Dez. 2017.

Secretaria de Direitos Humanos da Presidência da República. Orientações técnicas: serviços de acolhimento para crianças e adolescentes. Disponível em: < http://www.sdh.gov.br/assuntos/criancase-adolescentes/programas/pdf/orientacoestecnicas.pdf>. Acesso em: 07 dez. 2017.

CALIMAN, G. Paradigmas da exclusão social. Brasília: Unesco, 2008. Disponível em: < http://unesdoc.unesco.org/ images/0016/001622/162290por.pdf>. Acesso em: 07 dez. 2017.

COUTO, B. R.; YAZBEK, M. C.; RAICHELIS, R. A política nacional de assistência social e o SUAS: apresentando e problematizando fundamentos e conceitos. In: COUTO, B. R. et al. O Sistema Único de Assistência Social no Brasil: uma realidade em movimento. São Paulo: Cortez, 2012. p. 54-87.

DELGADO, G.; JACCOUD, L.; NOGUEIRA, R. P. Seguridade social: redefinindo o alcance da cidadania. Políticas sociais: acompanhamento e análise, Brasília, v. 1, n. 17, p. 17-37, 2009. Disponível em: <http://www.ipea.gov.br/portal/images/ stories/PDFs/politicas_sociais/bps_17_ vol001_completo.pdf>. Acesso em: 07 dez. 2017.

FERREIRA, M. A. et al. Saberes de adolescentes: estilo de vida e cuidado à saúde. Texto e contexto enfermagem, Florianópolis, v. 16, n. 2, p. 217-24, abr./ jun.2007. Disponível em: < http://www. scielo.br/pdf/tce/v16n2/a02v16n2>. Acesso em: 07 dez. 2017.

FLEURY, S. A. Seguridade social e os dilemas da inclusão social. Revista de Administração Pública, Rio de Janeiro, v. 39, n. 3, p. 449-467, mai./jun.2005. Disponível em: < http://www.redalyc.org/ pdf/2410/241021498001.pdf>. Acesso em: 07 dez. 2017.

MARCONI, M. A.; LAKATOS, E. M. Fundamentos de metodologia científica. São Paulo: Atlas, 2003.

MIRANDA, B. W. Os recursos humanos como instrumentos para a eficácia da administração pública. 2011, $52 \mathrm{f}$. Projeto Técnico (Especialização em Gestão Pública). Programa Nacional de Formação 
em Administração Pública, Universidade Federal do Paraná, Curitiba, 2011. Disponível em:<http://acervodigital.ufpr.br/ bitstream/handle/1884/33880/BRUNA\%20 WOINORVSKI\%20DE\%20MIRANDA. pdf?sequence $=1 \&$ isAllowed $=\mathrm{y}>$. Acesso em: 07 dez. 2017.

PEREIRA, P. A. P. A assistência social prevista na Constituição de 1988 e operacionalizada pela PNAS e pelo SUAS. Revista SER SOCIAL, Brasília, n. 20, p. 6383, jan./jun. 2007. Disponível em: < http:// periodicos.unb.br/index.php/SER_Social/ article/view/251>. Acesso em: 07 dez. 2017.

PONTA GROSSA. Conselho Municipal de Assistência Social. Resolução $\mathbf{n}^{\circ}$ 07/2016. Aprovação da inclusão do serviço de Acolhimento Institucional para Crianças e AdolescentesnainscriçãonoCMASdo Jovens com uma Missão - JOCUM. Disponível em: $\quad<$ http://www.pg.pr.gov.br/cmas/ wp-content/uploads/2011/07/Resolucao07-2016-Aprova\%C3\%A7\%C3\%A3oda-inclus\%C3\%A3o-do-servi\%C3\%A7ode-Acolhimento-Institucional-paraCrian\%C3\%A7 as-e-Adolescentes-nainscri\%C3\%A7\%C3\%A3o-no-CMAS-doJovens-com-uma-Miss\%C3\%A3o-JOCUM. pdf>. Acesso em: 07 dez. 2017.

Conselho Municipal de Assistência Social. Resolução no ${ }^{0}$ 12/2016. Cancelamento do convênio entre a Fundação Proamor de Assistência Social e o Jovens com uma Missão/JOCUM. Disponível em: $\quad<$ http://www.pg.pr.gov.br/cmas/wpcontent/uploads/2016/05/Resolucao-12cancelamento-convenio-JOCUM.pdf > . Acesso em: 07 Dez. 2017.

Secretaria Municipal de Assistência

Social. Central de Atendimento à Criança e ao Adolescente. Regimento interno:
Denominação, Sede e Fins. Ponta Grossa, 2013.

Secretaria Municipal de Gestão de Recursos Humanos. Edital Educador Social $\mathbf{n}^{\mathbf{0}}$ 004/2009. Ponta Grossa, 2009. Disponível em: < http://pontagrossa.pr.gov. br/files/concursos/16-09-2009_-_edital_de_ abertura.pdf $>$. Acesso em: 07 dez. 2017.

Secretaria Municipal de Gestão de Recursos Humanos. Edital Educador Social $\mathbf{n}^{\mathbf{0}}$ 004/2010. Ponta Grossa, 2010. Disponível em: < http://pontagrossa.pr.gov. br/files/concursos/22-12-2010_-_edital_de_ abertura.pdf>. Acesso em: 07 dez. 2017.

Secretaria Municipal de Gestão de Recursos Humanos. Edital de convocação. Disponível em: <http://pontagrossa. pr.gov.br/files/concursos/09-03-2015_-_ convocacao_-_educador_social_feminino_ educador_social_masculino.pdf $>$. Acesso em: 07 dez. 2017.

RICHARDSON, R. J. et al. Pesquisa social: métodos e técnicas. São Paulo: Atlas, 2008.

SILVA, M. E. S. Acolhimento institucional: a maioridade e o desligamento. 2010, 135f. Dissertação (Mestrado em Psicologia). Centro de Ciências Humanas, Letras e Artes, Programa de Pós-Graduação em Psicologia, Natal, 2010. Disponível em: < https://repositorio.ufrn.br/jspui/ bitstream/123456789/17469/1/MarthaESS_ DISSERT.pdf > . Acesso em: 07 dez. 2017.

SILVEIRA, J. I. Sistema Único de Assistência Social: institucionalidade e práticas. In: BATTINI, O. et al. SUAS: Sistema Único de Assistência Social em debate. São Paulo: Veras Editora, 2007. p.59-100.

SPOSATI, A. A menina LOAS: um processo de construção da Assistência Social. São Paulo: Cortez, 2007. 